\title{
Splenic lymphangioma in an adult
}

\author{
Safa A. Al-Shaikh, FRCPath, MBBS, Aalaa M. Mubarak, MD, Zainab F. Harb, MBBCh.
}

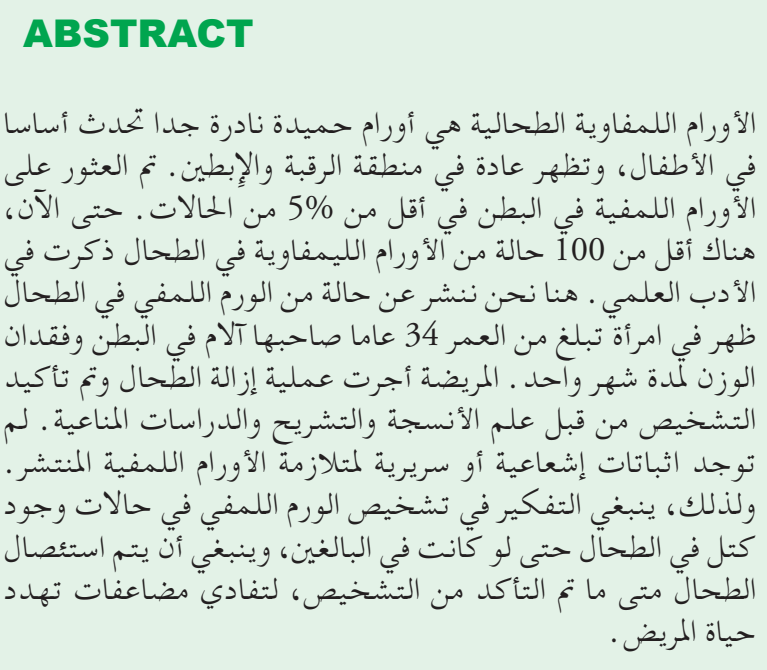

Splenic lymphangiomas are exceedingly rare benign neoplasms that occur mainly in children. They are commonly seen in the neck and axillary region. Abdominal lymphangiomas accounts for less than $5 \%$ of cases. So far, fewer than 100 cases of spleen lymphangiomas have been reported in the literature. In this paper, we present one case of solitary splenic lymphangioma in a 34-year-old woman who presented with abdominal pain and weight loss for one month. The patient underwent splenectomy and diagnosis was confirmed by histopathology and immunohistochemistry studies. There was no clinical or radiological evidence of diffuse lymphangiomatosis syndrome. This case indicates that splenic lymphangiomas should be considered in the differential diagnosis of splenic cystic masses, even in adults, and should be managed with splenectomy once diagnosed to prevent complications.

Saudi Med J 2017; Vol. 38 (11): 1148-1152 doi: 10.15537/smj.2017.11.20625

From the Department of Pathology, Salmaniya Medical Complex, Ministry of Health, Manama, Babrain.

Received 14th June 2017. Accepted 23rd August 2017.

Address correspondence and reprint request to: Dr. Safa A. Al-Shaikh, Consultant Pathologist, Department of Pathology, Salmaniya Medical Complex, Ministry of Health, Manama, Bahrain, E-mail:dr_salshaikh@hotmail.com

ORCID ID: orcid.org/0000-0002-8741-7188
J ymphangiomas are benign congenital malformations of the lymphatic vessels that manifest mainly in pediatric patients and infrequently in adults. The usual site for lymphangiomas is the head and neck region; however, they can occur in many different body organs, either as a systemic disease called lymphangiomatosis syndrome or as a single organ lesion. ${ }^{1-8}$ They rarely involve the spleen, especially in adults where they are found incidentally. The differential diagnosis is usually broad, and making an accurate diagnosis pre-operatively is a challenging task for clinicians. The treatment of choice is total resection of tumor in order to prevent serious complications. ${ }^{4}$

Case Report. Patient information. A 34-year-old woman, with diabetes mellitus, hypertension, hypothyroidism, arthritis, chronic renal impairment, and Hepatitis C, presented with a history of intermittent abdominal pain for one month. Her pain was intermittent, sharp, and sudden in onset, and started in the left upper quadrant and radiated to the back. The pain affected her daily activities. She also presented with a history of weight loss, but there was no history of bleeding, constipation, loss of appetite, or night sweats (Table 1).

Clinical findings. On examination, she had stable vitals, but there was tenderness in the left upper quadrant of the abdomen with deep palpations. Her initial blood investigations showed a hemoglobin measurement of 10 $\mathrm{g} / \mathrm{dL}$ and normal white blood and platelet counts. Her renal functions showed elevated creatinine $(4.05 \mathrm{mg} / \mathrm{L})$ and urea $(21.5 \mathrm{mmol} / \mathrm{L})$.

Diagnostic assessment. The results of an esophagogastroscopy study were unremarkable. A CT scan of the abdomen and chest with intravenous and oral contrast was carried out after nephrologist approval; this showed a normal-sized spleen with multiple variablesized well-defined hypodense cystic lesions. The largest lesion measured $2.5 \times 2.5 \mathrm{~cm}$ (Figure 1). No contrast enhancement was noted. The liver showed fatty changes only and the lung showed interstitial pneumonitis. No enlarged lymph nodes were detected in the abdomen, pelvis, or chest. A month later, she received a follow-up ultrasound and a repeated CT scan, which showed the 
Table 1 - The progress of the patient case from initial presentation to diagnosis, treatment and follow-up.

\begin{tabular}{|c|c|c|c|}
\hline Dates & $\begin{array}{l}\text { Summaries from initial and } \\
\text { follow up visits }\end{array}$ & Diagnostic testing & Interventions \\
\hline $8^{\text {th }}$ January 2017 & $\begin{array}{l}\text { Patient presented with left } \\
\text { upper abdominal pain. She was } \\
\text { admitted for investigations. }\end{array}$ & $\begin{array}{l}\text { CT Abdomen and chest with intravenous and oral contrast } \\
\text { show enlarged spleen with multiple variable size hypodense } \\
\text { masses. Blood investigations show hemoglobin of } 10 \mathrm{~g} / \mathrm{dL} \\
\text { and elevated urea and creatinine. }\end{array}$ & $\begin{array}{l}\text { Pain medications } \\
\text { No other intervention }\end{array}$ \\
\hline $12^{\text {th }}$ February 2017 & Follow up visit & $\begin{array}{l}\text { Doppler ultrasound of abdomen shows normal caliber and } \\
\text { blood flow patterns of splenic and portal veins, enlarged liver } \\
\text { with fatty infiltration, and normal size spleen with multiple } \\
\text { well defined hyperechoeic lesions. } \\
\text { Blood investigations show hemoglobin of } 8.9 \mathrm{~g} / \mathrm{dL} \text {. }\end{array}$ & No other intervention \\
\hline $14^{\text {th }}$ February 2017 & Follow up visit & $\begin{array}{l}\text { High resolution CT hest shows interstitial lung disease } \\
\text { (nonspecific interstitial pneumonitis), and no hilar or } \\
\text { mediastinal lymphadenopathy. }\end{array}$ & No other intervention \\
\hline $21^{\text {st }}$ February 2017 & $\begin{array}{l}\text { Follow up visit with } \\
\text { continuation of the patient } \\
\text { symptoms }\end{array}$ & $\begin{array}{c}\text { CT scan abdomen and pelvis with IV and oral contrasts } \\
\text { show stable appearance of the previously seen splenic } \\
\text { hypodense nodules. }\end{array}$ & $\begin{array}{l}\text { She was admitted for open } \\
\text { splenectomy (carried out } \\
\text { on } 28^{\text {th }} \text { February). She had } \\
\text { uneventful surgery. }\end{array}$ \\
\hline 26 $6^{\text {th }}$ April 2017 & $\begin{array}{l}\text { She presented with proximal } \\
\text { weakness in both thighs and } \\
\text { acute exacerbations of her } \\
\text { arthritis disease }\end{array}$ & $\begin{array}{l}\text { MRI both thighs without contrast show focal area of } \\
\text { abnormal signal intensity within the right vastus medialis muscle. }\end{array}$ & $\begin{array}{l}\text { Most likely it was } \\
\text { attributed to her } \\
\text { rheumatologic condition. }\end{array}$ \\
\hline
\end{tabular}

stable appearance of the previously seen lesions in the spleen.

Therapeutic intervention. Two months after the initial presentation, the splenic lesions continued to be symptomatic. Lymphoma was ruled out and the patient was admitted for open splenectomy surgery. She received pneumococcal vaccination 2 weeks prior to her surgery and intravenous antibiotics at the time of surgery. Her surgery was uneventful. No accessory spleens were found during the surgery. The splenectomy specimen was sent for histopathology evaluation. On macroscopic examination, the spleen measured $12.5 \times 9 \times 4.7 \mathrm{~cm}$ and weighed 167 grams. The outer surface was smooth but had multiple raised nodules. As revealed after slicing, these nodules corresponded to multiple bulging cystic spaces scattered among the whole spleen, mainly at both poles with a few in the center as well. The largest cystic space measured $2-3 \mathrm{~cm}$. These spaces were filled with thick gelatinous opaque material. The rest of the splenic tissue was unremarkable.

Follow-up and outcomes. On microscopic examination, the splenic parenchyma showed many subcapsular cystically dilated lymphatic spaces lined

Disclosure. Authors have no conflict of interests, and the work was not supported or funded by any drug company. by a single layer of flattened endothelial cells and filled with thick eosinophilic material (Figure 2). The adjacent splenic parenchyma was unremarkable. No calcifications, lamellations, atypia, or malignancy were seen. Immunohistochemical stains showed that cyst-lining cells were positive for CD31, factor VIII, and CD34, and focally positive for D2-40 (Figure 3). CD68 was present in the background histiocytes and the proliferation index represented by Ki-67 was low. The histopathology features matched those of a splenic lymphangioma. However, she had a stable recovery and she was discharged a few days after the operation. She was followed up one month after her surgery and the wound was healing nicely; she was later admitted for acute exacerbations and complications of her arthritis condition.

Discussion. Lymphangiomas are benign malformations of the lymphatic vessels. In more than $90 \%$ of cases they are found in the neck and axilla, where they are known as cystic hygromas. In less than $10 \%$ of cases they involve visceral organs as part of lymphangiomatosis syndrome, such as the mediastinum, gastrointestinal tract, and retroperitoneum. However, they rarely involve the spleen. The first reported case of spleen lymphangioma was in 1885 by Frink. ${ }^{1}$ So far, fewer than 100 cases have been reported in the literature. Between $80-90 \%$ of cases occur in children of less than 2 years, with only rare cases reported in adults. $^{2}$ In most cases, splenic lymphangioma is part 
of lymphangiomatosis syndrome, while solitary splenic lymphangioma is considered a much rarer disease, with few cases reported in the last 20 years, especially in adults. ${ }^{1-8}$

We have reviewed 8 cases of solitary splenic lymphangioma in adults. ${ }^{2-8}$ More than $90 \%$ of the cases involved females above the age of 25 , as with our case. The mean age of the affected patients was 46 years and the ages ranged from 28 to 70 years. In 4 cases (50\%), patients had experienced intermittent epigastric or

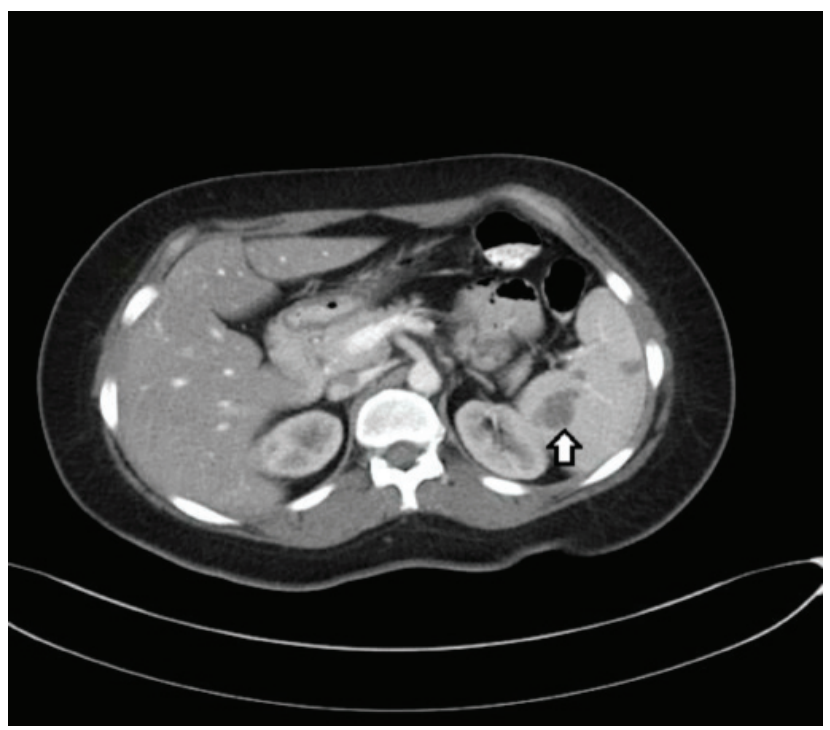

Figure 1 - A CT scan of abdomen shows multiple hypodense lesions in the spleen.

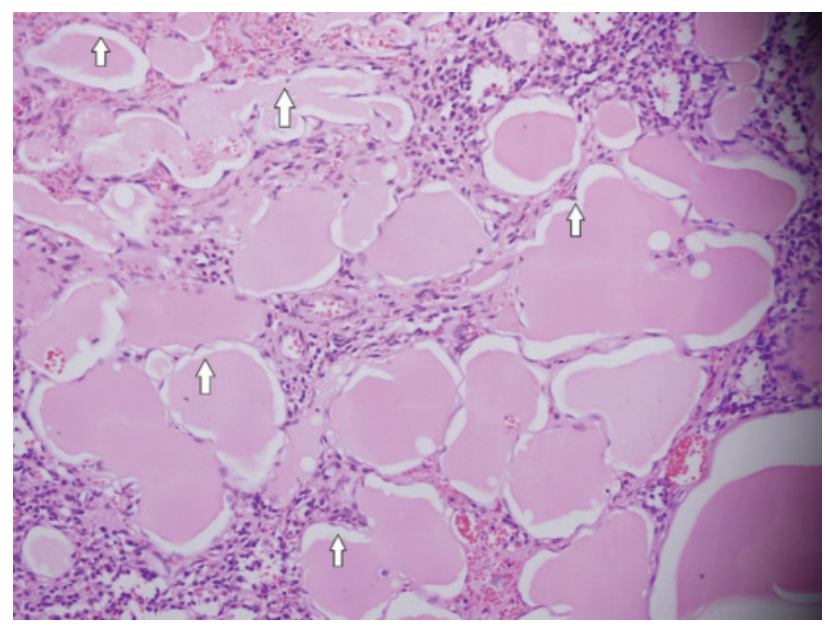

Figure 2 - Microscopic photo of spleen with variably size cystic spaces lined by flat endothelial cells and filled with acellular proteinaceous fluid $(\mathrm{x} 20)$. left upper abdominal pain over a period of months to years prior to presentation, as did our patient. It was an incidental finding in the rest of the cases. In all of the cases, patients were investigated by CT scans and managed by either open or laparoscopic splenectomy. All of them have an uneventful clinical course. ${ }^{2-8}$

Regarding our patient, splenic lymphangioma was symptomatic. The preoperative differential diagnosis included hydatid cysts, benign nonparasitic cysts including hemangioma, and lymphoma, which was raised because of the history of weight loss. The absence of lymphadenopathy ruled against the later diagnosis. In addition, the absence of contrast-enhancement or solid components radiologically was in favor of benign cysts. No serologic investigations were done to rule out hydatid disease in our patient. No image guided
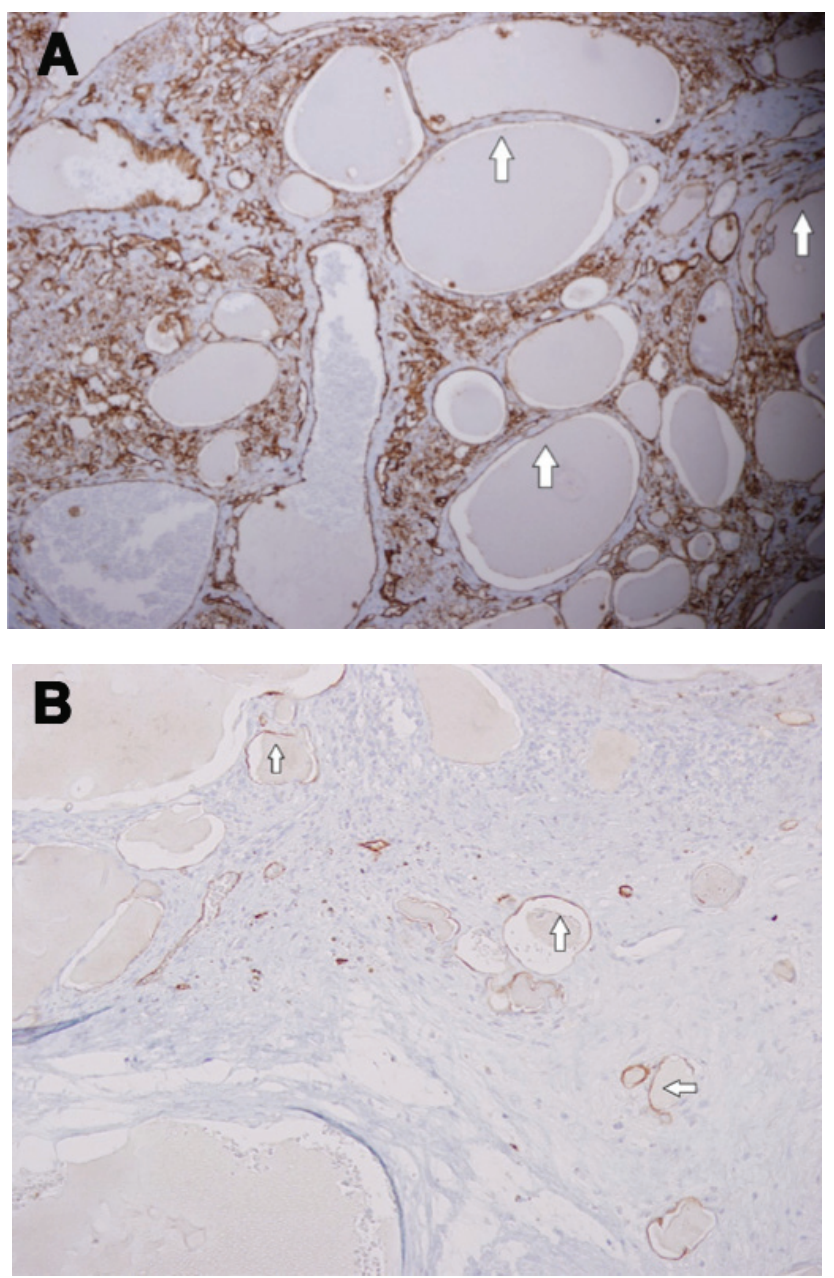

Figure 3 - Immunohistochemical studies showing A) diffuse CD31 positivity (x20) and B) focal D2-40 positivity in the endothelial cells $(\mathrm{x} 20)$. 
aspiration biopsy was carried out preoperatively to confirm the diagnosis; its usefulness is controversial due to the high risk of bleeding and inadequacy for diagnosis. $^{2}$ The lesion continued to be symptomatic but without progression, so it was wisely managed by elective splenectomy to prevent complications.

It is still controversial whether splenic lymphangioma is a neoplasm or a hamartoma. Most pathologists believe it is a hamartoma due to anomalous congenital expansion of the lymphatic vessels, bleeding, or inflammation leading to obstruction and subsequent lymphangiectasia. ${ }^{1,6}$

The clinical presentation of splenic lymphangiomas is usually related to the size of the spleen, but they can be asymptomatic or incidental findings during radiological assessment for other reasons. If they are large, they can cause abdominal pain, loss of appetite, nausea, vomiting, weight loss, and a palpable mass on physical examination. Imaging studies, preferably computerized tomography (CT) scans, typically show multiple subcapsular nonenhancing low-attenuation lesions. The presence of peripheral wall calcifications on radiological assessment may favor the diagnosis of cystic lymphangiomas. On angiography, these lesions are avascular. ${ }^{1,9}$

Macroscopically, splenic lymphangioma can come in solitary nodules, multiple nodules, or as diffuse lymphangiomatosis. Lymphangioma is usually subcapsular, because lymphatic vessels are only found in the subcapsular region. It consists of a single large cyst with a thick fibrous wall or multiple variable-size thin-walled cysts filled with clear fluid and separated by fibrous tissue or residual splenic tissue. In cases of diffuse lymphangiomatosis, the spleen is replaced by expanding cysts that result in little remaining normal parenchyma. ${ }^{1,3}$

Microscopically, they are classified into capillary, cavernous or cystic lymphangiomas. Cystic lymphangiomas are the most common. ${ }^{4}$ Generally, lymphangiomas consist of a single or multiple cystic spaces lined by attenuated endothelial cells. These cysts are filled with pink acellular proteinaceous material and their walls vary in thickness, from thin delicate to thick fibrous walls. The surrounding parenchyma may be normal or show congestion, fibrosis, and infiltration by occasional macrophages and lymphocytes. Rare cases showed malignant transformation. When in doubt of the histologic features, the endothelial origin of the cyst can be confirmed by demonstrating reactivity for CD34, CD31, factor VIII, vascular endothelial growth factor receptor 3, and podoplanin (D2-40). D2-40 is a selective marker for lymphatic endothelium and it stains lymphangiomas but not hemangiomas. Factor VIII, CD31, and CD34 stain the endothelial cells of both blood and lymphatic vessels. ${ }^{1,3}$

The differential diagnoses of splenic cystic lesions are classified into primary and secondary cysts. Secondary cysts (pseudocysts) account for nearly $80 \%$ of all splenic cystic lesions. They usually develop after trauma or previous infection or infarction. Histologically, they are lined by a fibrous wall only without specific lining cells. Primary cysts are subdivided into parasitic (60\%) and non-parasitic cysts. Parasitic cysts are mostly caused by echinococcal infection and called hydatid cysts. Non-parasitic cysts commonly include hemangiomas and epithelial cysts (epidermoid and mesothelial cysts), and rarely include lymphangiomas. Microscopically, hemangiomas represent vascular channels lined by endothelium and filled with red blood cells. They are positive for all endothelial markers except D2-40, which is only positive in lymphangioma. True splenic epidermoid cysts have stratified squamous epithelial lining and are positive for cytokeratin, while mesothelial cysts will have mesothelial lining and are positive for mesothelial cell markers such as calretinin. In contrast, hydatid cysts consist of three layers (inner germinal layer, intermediate laminated membrane, and outer fibrous layer) and contain protoscolices. ${ }^{1,9,10}$

The treatment of choice for splenic lymphangiomas is complete surgical resection, because other therapeutic modalities, including aspiration, drainage, and irradiation, have shown suboptimal results. Laparoscopic splenectomy is emerging as the procedure of choice in patients with a normal to moderately enlarged spleen, but contraindicated in patients with massive splenomegaly. Currently, partial splenectomy is increasingly advocated in order to avoid overwhelming post-splenectomy infection. ${ }^{2,3}$ Nevertheless, surgery should be advised immediately after the diagnosis has been established to avoid complications such as infection, rupture, pleural effusion, and tumor enlargement. The prognosis of splenic lymphangioma after surgical resection is excellent. The main complication is recurrence, which occurs in approximately $10 \%$ of patients, usually after an incomplete resection. The rate of malignant transformation is extremely low. ${ }^{1,8}$

In conclusion, lymphangiomas are rare benign neoplasms of the spleen that are especially rare in adults. Most patients present with abdominal pain due to mass effects, but it can also be asymptomatic. Despite being uncommon, they should always be considered in the differential diagnosis of cystic lesions of the spleen. Surgical excision is the treatment of choice in order to avoid possible lethal complications. 


\section{References}

1. Ioannidis I, Kahn AG. Splenic lymphangioma. Arch Pathol Lab Med 2015; 139: 278-282.

2. Rodríguez-Montes JA, Collantes-Bellido E, Marín-Serrano E, Prieto-Nieto I, Pérez-Robledo JP. Linfangioma esplénico. Un tumour raro. Presentaciónde 3 casos y revisión de la bibliografía. Cir Cir 2016; 84: 152-157.

3. Toval Mata JA, Carrasco Campos J, Ruiz López M, González Poveda I, Mera Velasco S. Linfangioma quístico esplénico. Cir Esp 2017; 95: 53-54.

4. Marwah N, Sangwan M, Ralli M, Verma R, Samal S. Cystic Lymphangioma of Spleen: A Case Report. International Journal of Scientific Study 2014; 2.

5. Verma M, Singla A, Malhotra C, Vashist M, Dalal S. Richa, et al. Lymphangioma of The Spleen In An Adult. The Internet Journal of Surgery 2013; 30.
6. Verghese BG, Kashinath SK, Ravi Kanth R. Lymphangioma of the spleen. A rare Tumor rarely seen in an Adult: A case report and a comprehensive Literature review. Euroasian J HepatoGastroenterol 2013; 3: 64-69.

7. Yang F, Chen WX. Splenic lymphangioma that manifested as a solid-cystic mass: a case report. World J Gastroenterol 2013; 19: 781-783.

8. Unver M, Ozturk M, Erol V, Kebabcı E, Pehlivanoğlu K, Zalluhoğlu N, et al. Laparoscopic Treatment of Splenic Lymphangioma: A Rare Case in Adults. Journal of Surgery 2014; 2: 32-34.

9. Thipphavong S, Duigenan S, Schindera ST, Gee MS, Philips S. Nonneoplastic, benign, and malignant splenic diseases: crosssectional imaging findings and rare disease entities. AJR Am J Roentgenol 2014; 203: 315-322.

10. Golmohammadzadeh H, Maddah G, Shams Hojjati Y, Abdollahi A, Shabahang H. Splenic cysts: analysis of 16 cases. Caspian J Intern Med 2016; 7: 217-221.

\section{Case Reports}

Case reports will only be considered for unusual topics that add something new to the literature. All Case Reports should include at least one figure. Written informed consent for publication must accompany any photograph in which the subject can be identified. Figures should be submitted with a 300 dpi resolution when submitting electronically. The abstract should be unstructured, and the introductory section should always include the objective and reason why the author is presenting this particular case. References should be up to date, preferably not exceeding 15 . 